\title{
CRESCIMENTO DE MILHO EM LATOSSOLO COM APLICAÇÃO DE ÁGUA
} RESIDUÁRIA DE SUINOCULTURA

\author{
Edcarlos da Silva Souza',Cleiton Fernando Barbosa Brito', Varley Andrade \\ Fonseca $^{1}$ e Felizarda Viana Bebé ${ }^{1}$ \\ ${ }^{1}$ Instituto Federal de Educação, Ciência e Tecnologia Baiano, Campus Guanambi, \\ BA - Brasil. E-mail: cleiton.ibce@hotmail.com
}

\section{Recebido em: 08/04/2016 - Aprovado em: 30/05/2016 - Publicado em: 20/06/2016 DOI: 10.18677/Enciclopedia_Biosfera_2016_032}

\begin{abstract}
RESUMO
Este estudo teve como objetivo avaliar o uso de água residuária de suinocultura como fonte alternativa de nutrientes no crescimento inicial do milho. O delineamento experimental utilizado foi o inteiramente casualizado constituído de quatro doses de água residuária $\left(0,112,224\right.$ e $\left.448 \mathrm{~m}^{3} \mathrm{ha}^{-1}\right)$ com quatro repetições. Aos 49 dias após o plantio foram avaliadas as variáveis altura, número de folhas, diâmetro do colmo, área foliar e no final do período de avaliações foi determinado matéria seca da parte aérea da planta. $O$ aumento das doses de ARS possibilitaram incrementos lineares da altura, diâmetro do colmo e área foliar de plantas de milho. A aplicação de ARS mostrou ser uma alternativa para adubação da cultura do milho, pois, influenciaram diretamente variáveis importantes da cultura do milho.
\end{abstract}

PALAVRAS-CHAVE: Adubação orgânica, água residuária de suinocultura, Zea mays

\section{GROWTH OF CORN IN APPLICATION OF WATER WITH LATOSOL SWINE WASTEWATER}

\begin{abstract}
This study aimed to evaluate the use of swine wastewater as an alternative source of nutrients in the early growth of corn. The experimental design was completely randomized consisted of four wastewater doses (0,112, 224 and $448 \mathrm{~m}^{3}$ ha-1) with four replications. After 49 days after planting were evaluated variables height, leaf number, stem diameter, leaf area and at the end of the ratings period was determined dry matter of the aerial part of the plant. Increasing doses ARS allowed linear increments of height, stem diameter, leaf area of corn plants. The application of ARS could be an alternative for fertilization of corn, therefore, directly influenced important variables of corn.
\end{abstract}

KEYWORDS: Organic fertilizer, swine wastewater, Zea mays

\section{INTRODUÇÃO}

O milho (Zea mays L.) é cultivado em todo o Brasil e apresenta grande importância econômica, devido às diversas formas de sua utilização e ao fato de ser cultivado tanto pela agricultura empresarial quanto familiar. Dentre os aspectos que ENCICLOPÉDIA BIOSFERA, Centro Científico Conhecer - Goiânia, v.13 n.23; p. 3692016 
devem ser considerados no cultivo de milho, a disponibilidade de nutrientes para a cultura é um fator primordial. Desta forma, com o aumento dos custos de produção dos fertilizantes químicos faz-se necessária a utilização de diversas alternativas dentro da própria propriedade, como por exemplo, os resíduos provenientes da criação animal.

A aplicação de resíduos agropecuários apresenta potencial para suprir a demanda por nutrientes de forma sustentável (CASTOLDI et al., 2011). Neste sentido, a água residuária de suinocultura (ARS) apresenta-se como uma fonte alternativa de nutrientes, contendo matéria orgânica, macro e micronutrientes (CABRAL et al., 2011; SERPA FILHO et al., 2013).

O uso da ARS como fertilizante pode ser uma das alternativas de reciclagem desse dejeto, pois, os nutrientes nele contidos, após mineralizados, são disponibilizados à absorção pelas plantas (BATISTA et al., 2014). Desta forma, com a utilização da ARS não ocorre acúmulo desse material na propriedade, além de proporcionar redução da aplicação de fertilizantes químicos. Além disso, a ARS fornece agua às plantas, principal fator limitante da produção no semiárido.

Pesquisas com aplicação de ARS verificaram que, quando feita em quantidades adequadas, promove maior produção de forragem de Brachiaria brizantha e, influenciam diretamente em variáveis de crescimento da cultura do milho (SERAFIM \& GALBIATTI, 2012; MORAES et al., 2014). No entanto, pesquisas com doses de ARS são escassas, principalmente na região semiárida. Neste contexto, o objetivo deste trabalho foi avaliar a utilização de água residuária de suinocultura como fonte alternativa de nutrientes no crescimento inicial do milho.

\section{MATERIAL E MÉTODOS}

O experimento foi conduzido em ambiente protegido (sombrite $50 \%$ ), na área experimental do Instituto Federal de Educação, Ciência e Tecnologia Baiano Campus Guanambi, localizado no Município de Guanambi, Micro Região da Serra Geral, Sudoeste da Bahia com latitude 1493'30" sul, e longitude 42\%6'53" oeste e altitude de $525 \mathrm{~m}$. O clima da região é do tipo Aw pela classificação de Köppen com média de precipitação pluviométricas anuais de 663,69 mm e temperatura média de $26^{\circ} \mathrm{C}$.

O cultivo do milho foi realizado em vasos de polietileno que foram preenchidos com $10 \mathrm{~kg}$ de um Latossolo Vermelho Amarelo de textura média coletado da camada de $0-20 \mathrm{~cm}$ de profundidade. As sementes utilizadas foram provenientes de produtores familiares da região, que ainda cultivam o milho crioulo. Antes da instalação do experimento foi coletada uma amostra de solo que posteriormente foi seca ao ar, destorroada e peneirada com malha de $2 \mathrm{~mm}$, para caracterização química (Tabela 1).

TABELA 1. Caracterização química do solo na profundidade $0-20 \mathrm{~cm}$ antes da instalação do experimento.

\begin{tabular}{|c|c|c|c|c|c|c|c|c|c|c|c|c|}
\hline Profundidade & $\mathrm{pH}$ & $P$ & K & $\mathrm{Ca}$ & $\mathrm{Mg}$ & Al & $\mathrm{H}$ & SB & $\mathrm{t}$ & $\mathrm{T}$ & V & $\mathrm{m}$ \\
\hline & $\mathrm{H}_{2} \mathrm{O}$ & $\mathrm{mg} \mathrm{dm}^{-3}$ & ----- & --- & $\mathrm{cm}$ & $\mathrm{dm}$ & -- & --- & - & & & -- \\
\hline $0-20 \mathrm{~cm}$ & 5,5 & 8 & 0,38 & 1,3 & 0,8 & 0,2 & 2,3 & 2,5 & 2,7 & 5 & 50 & 7 \\
\hline
\end{tabular}


O delineamento experimental utilizado foi 0 inteiramente casualizado, constituído de quatro doses de água residuária de suinocultura (ARS) $(0,112,224$ e $448 \mathrm{~m}^{3} \mathrm{ha}^{-1}$ ) com quatro repetições, totalizando 16 unidades experimentais. $\mathrm{O}$ plantio foi realizado com cinco sementes, na profundidade de $2 \mathrm{~cm}$, e, após germinação realizou-se o desbaste deixando três plantas por vaso. A ARS foi aplicada manualmente, com auxilio de um regador, aos 11, 18 e 25 dias após o plantio (DAP).

A ARS utilizada foi obtida do setor de suinocultura do IF Baiano, Campus Guanambi. As doses de ARS adotadas foram em função do teor de nitrogênio $(\mathrm{N})$ de sua composição para fornecer $0,100,200$ e $400 \mathrm{~kg} \mathrm{~N} \mathrm{ha}^{-1}$, conforme pesquisa realizada por ZANUZO \& SAMPAIO (2012). Aos 49 DAP foram avaliadas as variáveis: altura, número de folhas, diâmetro do colmo, área foliar e no final do período de avaliações foi determinado matéria seca da parte aérea da planta.

A altura das plantas foi medida da superfície do solo até a base da última folha com auxilio de fita métrica, o número de folhas por contagem direta e o diâmetro do colmo foi medido com auxílio de paquímetro na metade do primeiro entrenó expandido (BELEZE et al., 2003). Para encontrar a área foliar de cada planta, multiplicou-se sua maior largura pelo comprimento, multiplicando-se em seguida essa área pelo coeficiente de 0,75 e posteriormente pelo número de folhas de cada planta (FRANCIS et al., 1969). Para estas variáveis foram avaliadas três plantas dentro da parcela útil de cada tratamento e repetição, obtendo assim o valor médio basal da parcela. Para determinação da matéria seca a parte aérea foi colocada em estufa a $65^{\circ} \mathrm{C}$ até obtenção de massa constante conf orme método de Weende.

Os resultados das variáveis foram submetidos à análise de variância e regressão no programa estatístico "R", R Development Core Team (2012). Os ajustes das equações de regressão foram com base na adequação do modelo ao fenômeno estudado, significância dos parâmetros da regressão pelo teste t a 5 \% de probabilidade e no coeficiente de determinação ajustado $\left(R^{2}\right)$.

\section{RESULTADOS E DISCUSSÃO}

Na Tabela 2 observa-se o resumo da análise de variância com os respectivos quadrados médios para a variável altura, número de folhas, diâmetro do colmo, área foliar e matéria seca em função da aplicação de diferentes doses de agua residuária de suíno (ARS). Houve efeito significativo das doses de ARS para a variável altura, diâmetro do colmo e área foliar.

TABELA 2. Resumo da análise de variância com os respectivos quadrados médios para a variável altura, número de folhas, diâmetro do colmo, área foliar e matéria seca em função da aplicação de diferentes doses de agua residuária de suíno (ARS).

\begin{tabular}{ccccccc}
\hline \multicolumn{7}{c}{ Quadrados médios } \\
\hline Fontes de & GL & $\begin{array}{c}\text { Altura } \\
\text { Variação }\end{array}$ & $\begin{array}{c}\mathrm{N}^{\circ} \text { de } \\
\text { Folhas }\end{array}$ & $\begin{array}{c}\text { Diâmetro do } \\
\text { colmo }(\mathrm{cm})\end{array}$ & $\begin{array}{c}\text { Área foliar } \\
\left(\mathrm{cm}^{2}\right)\end{array}$ & $\begin{array}{c}\text { Matéria seca } \\
(\mathrm{g})\end{array}$ \\
\hline Doses & 3 & $204,59^{*}$ & $0,60^{\mathrm{NS}}$ & $0,08^{*}$ & $304351^{\star *}$ & $204,36^{\mathrm{NS}}$ \\
Resíduo & 12 & 19,44 & 0,34 & 0,01 & 59729 & 281,04 \\
Media & & 92,39 & 6,70 & 1,44 & 1611,25 & 53,66 \\
CV $(\%)$ & & 4,77 & 8,77 & 6,99 & 15,16 & 31,23 \\
\hline
\end{tabular}

${ }^{N S}$ não significativo, * significativo a $5 \% \mathrm{e}^{* *}$ significativo a $1 \%$ de probabilidade pelo teste $\mathrm{F}$. 
Os resultados indicam que a ARS disponibiliza nutrientes para 0 desenvolvimento da planta. ZANUZO \& SAMPAIO (2012) afirmam que a ARS tem sido usada em áreas de culturas como fonte de nutrientes, tendo o $\mathrm{N}$ e o $\mathrm{P}$ como dois importantes constituintes do dejeto sob o ponto de vista nutricional de plantas.

DAL MORO et al. (2010) avaliando o efeito da aplicação com dejetos líquidos de suíno (DLS) na cultura do milho, verificaram que mesmo os DLS apresentando condições específicas de nutrição para os diferentes tratamentos, demonstraram efeito significativo somente para a variável inserção de espiga, não sendo significativo para as demais variáveis. Conforme pode ser observado na Tabela 2, no presente estudo, somente as variáveis $n^{\circ}$ de folh as e matéria seca não apresentaram efeito significativo.

A altura de plantas de milho ajustou-se ao modelo linear em função da aplicação das doses de ARS (Figura 1). Dessa forma, até a dose $448 \mathrm{~m}^{3} \mathrm{ha}^{-1}$ de ARS, as plantas de milho apresentaram incremento, o que era esperado, pois as plantas encontravam-se em fase inicial de crescimento e desenvolvimento. Este incremento linear pode ser atribuído a possível liberação de nutrientes da ARS, principalmente $\mathrm{N}$, pois, na sua forma liquida a maior parte do $\mathrm{N}$ encontra-se na forma amoniacal (mineral), ou seja, prontamente disponível para o desenvolvimento da maioria das culturas (SERAFIM \& GALBIATTI, 2012).

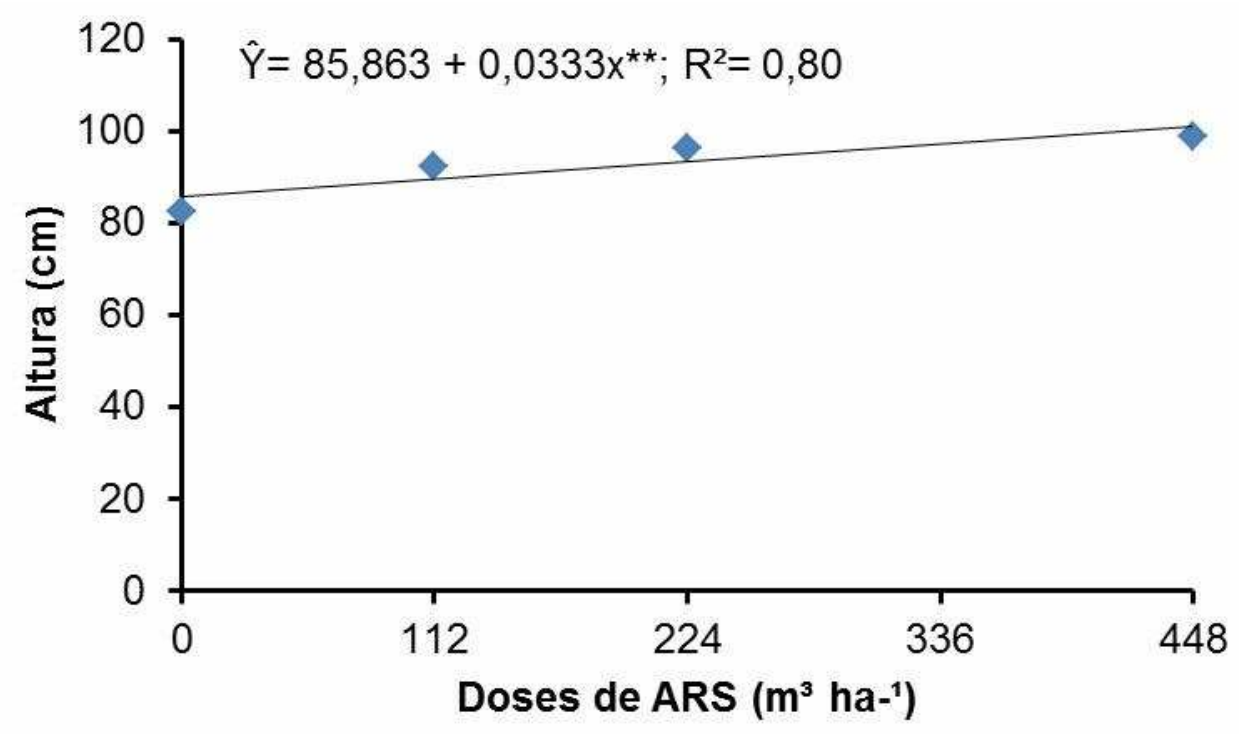

FIGURA 1. Altura de plantas de milho em função de doses de água residuária de suíno (ARS).

REZENDE et al. (2009) avaliaram o milho fertirrigado com dejetos líquidos de suínos (DLS) para ensilagem e observaram as maiores médias de altura de plantas nos tratamentos que receberam $150 \mathrm{~m}^{3}$ de DLS ha ${ }^{-1}$. Assim como no presente estudo, estes resultados podem ser atribuídos ao efeito da disponibilidade de nutrientes sobre esta característica das plantas (SERAFIM \& GALBIATTI, 2012).

A ARS pode ser uma alternativa bastante viável, pois, além de fornecer nutrientes as culturas, fornece água que é fator limitante para a maioria das culturas no semiárido. No entanto, a magnitude de resposta da cultura do milho ao uso de ARS pode variar em função das condições edafoclimáticas e da composição dos 
dejetos, tanto relativa ao $\mathrm{N}$ como também aos demais nutrientes (GIACOMINI \& AITA, 2008).

A aplicação da ARS influenciou positivamente o diâmetro do colmo plantas de milho e o modelo linear foi o que melhor se ajustou aos valores (Figura 2). Os resultados indicam a importância do uso da água residuária na agricultura, corroborando com COSTA et al. (2009), que verificaram para todas as variáveis de crescimento do milho, inclusive diâmetro do caule, respostas superiores para os tratamentos que receberam água residuária.

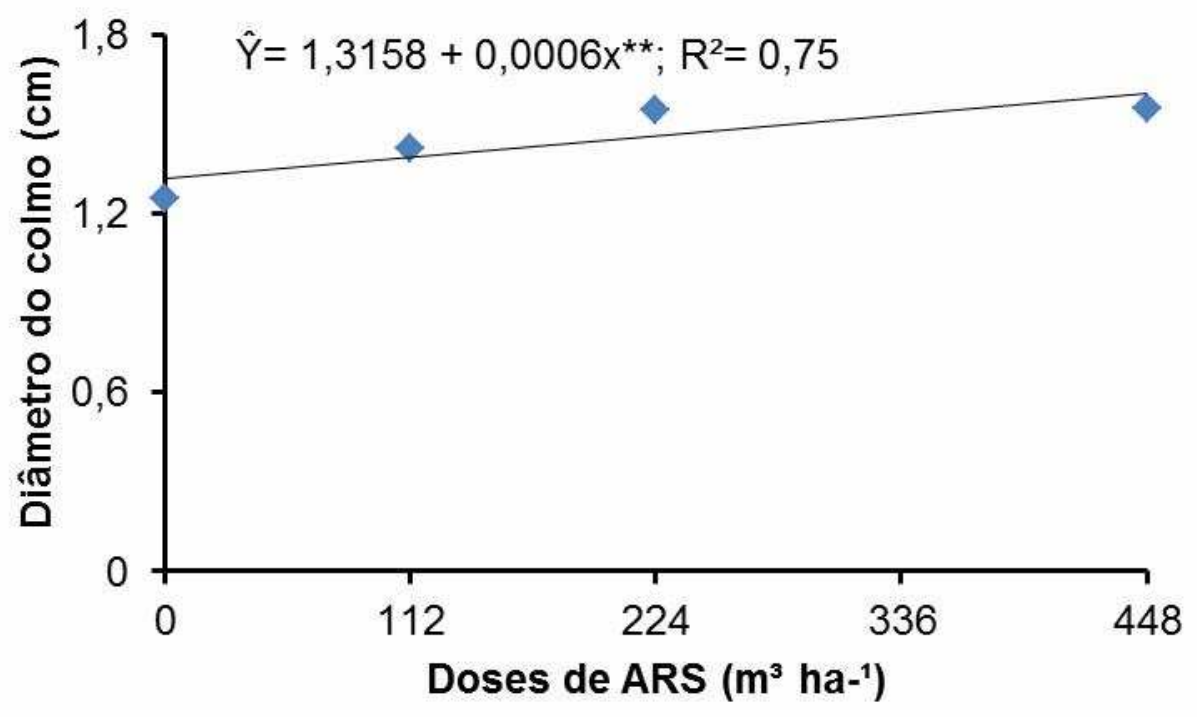

FIGURA 2. Diâmetro do colmo de plantas de milho em função de doses de água residuária de suíno (ARS).

O diâmetro do colmo possui função importante para as plantas de milho, pois, atua principalmente no armazenamento de sólidos solúveis que serão utilizados posteriormente na formação dos grãos. Em virtude disso, o aumento do diâmetro do colmo proporcionado pela ARS no crescimento inicial pode ser indicativo de aumento da produtividade do milho (BRITO et al., 2014).

A área foliar do milho com aplicação de ARS ajustou-se ao modelo linear (Figura 3). Os valores médios de área foliar evidenciam a superioridade da aplicação da ARS em relação à testemunha, pois, a aplicação de uma unidade de ARS proporcionou incremento de $1,37 \mathrm{~cm}^{2}$ de área foliar. Estes incrementos, possivelmente, estão relacionados a liberação de nutrientes pela ARS e são consequência dos incrementos encontrados também nas variáveis altura e diâmetro do colmo. 


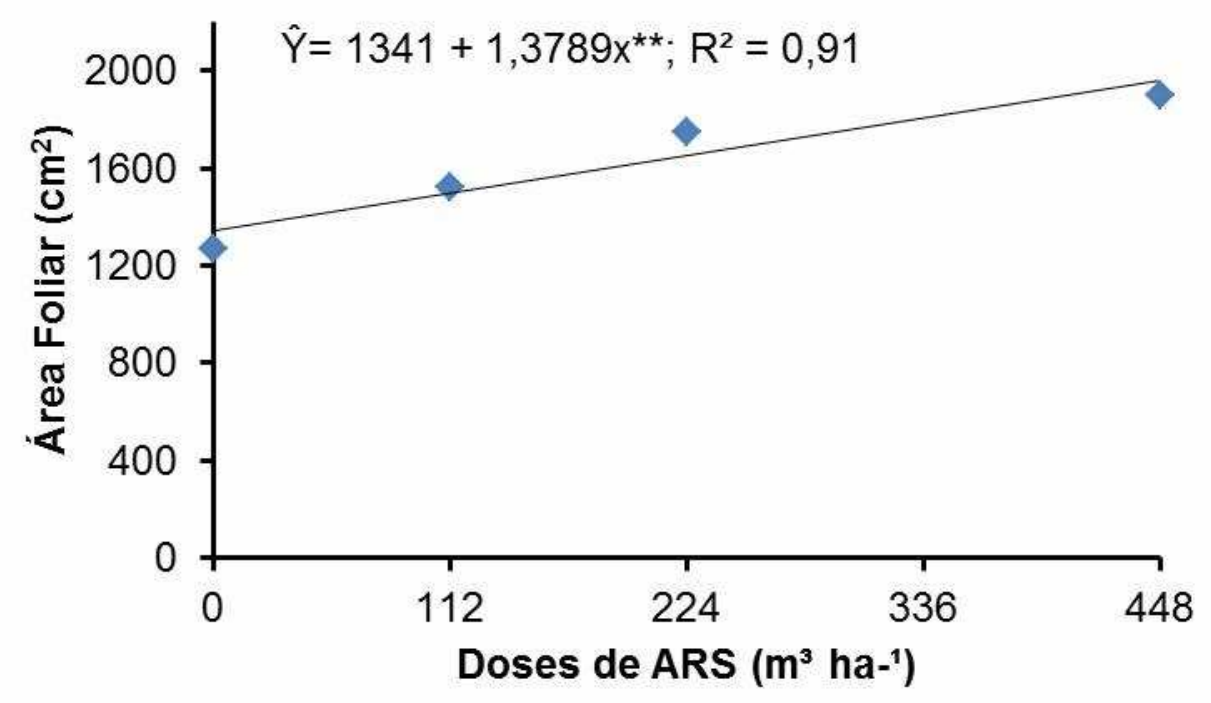

FIGURA 3. Área foliar de plantas de milho em função de doses de água residuária de suíno (ARS).

MENEGHETTI et al. (2012) avaliando a composição mineral e crescimento do minimilho sob água residuária de suinocultura combinada com adubação química verificaram que o incremento da adubação com uso de ARS proporcionou maiores estaturas de plantas, área foliar, índice de área foliar, número de folhas por planta e taxa de crescimento absoluto. Desta forma, a aplicação de ARS pode ser uma alternativa viável, para ser usada tanto de forma isolada, como no presente estudo, ou, combinada com a adubação química reduzindo a quantidade desta.

A área foliar é importante pela estreita correlação entre as taxas fotossintéticas e transpiração das plantas de milho, uma vez que reflete a capacidade da planta em interceptar as radiações e efetuar trocas gasosas com o ambiente, constituindo-se assim em importante indicativo da produtividade das culturas (VIEIRA JUNIOR et al. 2006). Com isso, plantas que apresentem área foliar elevada no desenvolvimento inicial podem indicar produtividades elevadas no final do ciclo.

Segundo MATA et al. (2010) para garantir o aumento da área foliar, é importante que a disponibilidade hídrica no solo esteja adequada, garantindo por consequência o desenvolvimento e rendimentos satisfatórios pela cultura. Sendo assim, a aplicação de ARS, torna-se uma alternativa importante, pois, garante a disponibilidade de nutrientes e água para a cultura, sendo estes os principais fatores limitantes para a produção de milho no semiárido.

\section{CONCLUSÃO}

O aumento das doses de ARS possibilitaram incrementos lineares da altura, diâmetro do colmo e área foliar de plantas de milho.

A aplicação de ARS mostrou ser uma alternativa para adubação da cultura do milho, pois influenciaram diretamente variáveis importantes da cultura.

\section{REFERÊNCIAS}


BATISTA, R. O.; MARTINEZ, M. A.; PAIVA, H. N.; BATISTA, R. A.; CECON, P. R. O efeito da água residuária da suinocultura no desenvolvimento e qualidade de mudas de Eucalyptus urophylla. Ciência Florestal, v. 24, n. 1, p. 127-135, 2014. Disponível em: < http://www.redalyc.org/articulo.oa?id=53430144012>. ISSN 0103-9954. Acesso em 22/02/2016

BELEZE, J. R. F.; ZEOULA, L. M.; CECATO, U.; DIAN, P. H. M.; MARTINS, E. M.; FALCÃO, A. J. S. Avaliação de Cinco Híbridos de Milho (Zea mays, L.) em Diferentes Estádios de Maturação- Produtividade, Características Morfológicas e Correlações. Revista Brasileira de Zootecnia, v.32, n.3, p.529-537, 2003. Disponível em: <http://dx.doi.org/10. 1590/S1516-35982003000300004> Acesso em 20/05/2016. Doi:10. 1590/S1516-35982003000300004

BRITO, C. F. B.; FONSECA, V. A.; BEBÉ, F. V.; SANTOS, L. G. Desenvolvimento inicial do milho submetido a doses de esterco bovino. Revista Verde, v. 9, n. 3, p. 244 - 250, 2014.

CABRAL, J.R.; FREITAS, P.S.L.; REZENDE, R.; MUNIZ, A.S.; BERTONHA, A. Impacto da água residuária de suinocultura no solo e na produção de capimelefante. Revista Brasileira de Engenharia Agrícola e Ambiental, v.15, n.8, p.823-831, 2011. Disponível em: http://dx.doi.org/10.1590/S141543662011000800009. Acesso em 12/01/2016. doi: 10.1590/S141543662011000800009

CASTOLDI, G.; COSTA, M.S.S.M.; COSTA, L.A.M.; PIVETTA, L. A.; STEINER, F. Sistemas de cultivo e uso de diferentes adubos na produção de silagem e grãos de milho. Acta Scientiarum Agronomy, v. 33, n. 1, p. 139-146, 2011. Disponível em: <http://dx.doi.org/10.4025/actasciagron.v33i1.766>. Acesso em 23/01/2016. doi:10.4025/actasciagron.v33i1.766

COSTA, F. X.; LIMA, V. L. A.; BELTRÃO, N. E. M.; AZEVEDO, C. A. V.; SOARES, F. A. L.; ALVA, I. D. M. Efeitos residuais da aplicação de biossólidos e da irrigação com água residuária no crescimento do milho. Revista Brasileira de Engenharia Agrícola e Ambiental, v.13, n.6, p.687-693, 2009. Disponível em: <http://dx.doi.org/10.1590/S1415-43662009000600004>. Acesso em 23/01/2016. doi: $10.1590 / S 1415-43662009000600004$

DAL MORO, H. G.; MOREIRA, G. C.; SONCELA, A. S. Efeito da aplicação com dejetos líquidos de suíno na cultura do milho. Cultivando o Saber, Cascavel, v.3, n.4, p.154-166, 2010.

FRANCIS, C. A.; RUTGER, J. N.; PALMER, A. F. E. A rapid method for plant leaf área estimation in maize (Zea mays L.). Crop Science, n. 9, p.537-539, 1969.

GIACOMINI, S. J.; AITA, C. Cama sobreposta e dejetos líquidos de suínos como fonte de nitrogênio ao milho. Revista Brasileira de Ciência do Solo, v.32, p.195205, 2008. Disponível em: <http://dx.doi.org/10.1590/S0100-06832008000100019>. Acesso em 25/01/2016. doi: 10.1590/S0100-06832008000100019 
MATA, J. F.; SILVA, J. C.; RIBEIRO, J. F.; AFFÉRRI, F.S.; VIEIRA, L. M. Produção de milho híbrido sob doses de esterco bovino. Pesquisa Aplicada \& Agrotecnologia, v.3, n.3, 2010.

MENEGHETTI, A. M.; NÓBREGA, L. H. P.; SAMPAIO.; S. C.; FERQUES R. G. Mineral composition and growth of babycorn under swine wastewater combined with chemical fertilization. Revista Brasileira de Engenharia Agrícola e Ambiental, v.16, n.11, p.1198-1205, 2012. Disponível em: <http://dx.doi.org/10.1590/S141543662012001100008>. Acesso em 02/02/2016. doi: 10.1590/S141543662012001100008

MORAES, M. T.; ARNUTI, A.; SILVA, V. R.; SILVA, R. F.; BASSO, C. J.; DA ROS, C. O.; Dejetos líquidos de suínos como alternativa a adubação mineral na cultura do milho. Semina: Ciências Agrárias, v. 35, n. 6, p. 2945-2954, 2014. Disponível em:< http://dx.doi.org/10.5433/1679-0359.2014v35n6p2945>. Acesso em 02/02/2016. doi:10.5433/1679-0359.2014v35n6p2945

R DEVELOPMENT CORE TEAM, R. A language and environment for statistical computing, Vienna, Austria: R Foundation for Statistical Computing, 2012.

REZENDE, A.V.; VALERIANO, A. R.; VILELA, H. H.; CESARINO, R. S.; SALVADOR, F. M.; SILVEIRA, C. H. Milho fertirrigado com dejetos líquidos de suínos para ensilagem. Revista Agrarian, v.2, n.5, p.7-20, jul./set. 2009.

SERAFIM, R. S.; GALBIATTI, J. A. Efeito da aplicação de água residuária de suinocultura na Brachiaria brizantha cv marandu. Revista Colombiana de Ciência Animal, v.4, n.1, 185-203, 2012.

SERPA FILHO, R.; SEHNEM, S.; CERICATO, A.; SANTOS JUNIOR, S.; FISCHER, A. Compostagem de dejetos de suínos. Revista em Agronegócios e Meio Ambiente, v. 6, n. 1, p. 47-78, 2013.

VIEIRA JUNIOR, P. A.; NETO, D. D.; CICERO, S. M.; CASTRO, L. A.; MANFRON, P. A.; MARTIN, T. N. Estimativa da área foliar em milho através de análise de imagens. Revista Brasileira de Milho e Sorgo, v.5, n.1, p.58-66, 2006.

ZANUZO, L.; SAMPAIO, S. C. Comportamento de cátions em solo cultivado com milho irrigado com água residuária de suinocultura. Irriga, Botucatu, v. 17, n. 1, p. 56-70, janeiro-março, 2012. Disponível em: <http://dx.doi.org/10.15809/irriga.2012v17n1p56>. Acesso em 18/01/2016 doi: 10.15809/irriga.2012v17n1p56 